\title{
Core Competencies in Disaster Management and Humanitarian Assistance: A Systematic Review
}

\author{
Alba Ripoll Gallardo, MD; Ahmadreza Djalali, MD, PhD; Marco Foletti, MD; \\ Luca Ragazzoni, MD; Francesco Della Corte, MD; Olivera Lupescu, MD, PhD; \\ Chris Arculeo, DipEP; Gotz von Arnim, Dipl-Ing; Tom Friedl; Michael Ashkenazi, MPhil, \\ PhD; Philipp Fisher, MD; Boris Hreckovski, MD; Amir Khorram-Manesh, MD, PhD; \\ Radko Komadina, MD, PhD; Konstanze Lechner, Dipl, PhD; Marc Stal, \\ Dipl Geo; Cristina Patru, MD, PhD; Frederick M. Burkle, Jr., MD, MPH, DTM; \\ Pier Luigi Ingrassia, MD, PhD
}

\section{ABSTRACT}

Disaster response demands a large workforce covering diverse professional sectors. Throughout this article, we illustrate the results of a systematic review of peer-reviewed studies to identify existing competency sets for disaster management and humanitarian assistance that would serve as guidance for the development of a common disaster curriculum. A systematic review of English-language articles was performed on PubMed, Google Scholar, Scopus, ERIC, and Cochrane Library. Studies were included if reporting competency domains, abilities, knowledge, skills, or attitudes for professionals involved disaster relief or humanitarian assistance. Exclusion criteria included abstracts, citations, case studies, and studies not dealing with disasters or humanitarian assistance. Thirty-eight papers were analyzed. Target audience was defined in all articles. Five references (13\%) reported cross-sectorial competencies. Most of the articles (81.6\%) were specific to health care. Eighteen (47\%) papers included competencies for at least 2 different disciplines and 18 (47\%) for different professional groups. Nursing was the most widely represented cadre. Eighteen papers (47\%) defined competency domains and $36(94 \%)$ reported list of competencies. Nineteen articles (50\%) adopted consensus-building to define competencies, and 12 (31\%) included competencies adapted to different professional responsibility levels. This systematic review revealed that the largest number of papers were mainly focused on the health care sector and presented a lack of agreement on the terminology used for competency-based definition. (Disaster Med Public Health Preparedness. 2015;9:430-439)

Key Words: disaster medicine education, competency-based education, professionalization, humanitarian aid

$\mathrm{G}$ lobally, 2013 was characterized by 330 natural disasters. ${ }^{1}$ The poorest countries are typically the most affected, with a total of 5 low- or lower-middle income countries among the top 10 in terms of disaster mortality. Aid workers are often required to operate within disrupted political systems with no pre-existing disaster plans ${ }^{2}$ and to perform tasks that fall outside their area of expertise, especially the management of refugees and internally displaced populations, communicable diseases, and the lack of critical resources. ${ }^{3}$ Lessons learned from relevant disasters-such as Haiti (2010), the Asian tsunami (2004), the Haiyan Typhoon (2013), and the current Ebola virus disease tragedies in West Africacall for attention to the limited capability of foreign medical teams to meet challenges posed by complex emergencies. ${ }^{4-9}$ These concerns have prompted the international community to devise means for the development of both competence and professionalism within the humanitarian assistance sector. ${ }^{4,6}$

Disaster response demands a large workforce with diverse professional disciplines, subspecialty categories, and levels of professional experience and cultural expertise. Regardless of their professional background, education for personnel operating in disaster situations should be based on the acquisition of task-related, profession-specific, and cross-disciplinary competencies obtained through accredited education and training programs implemented by academically affiliated centers. ${ }^{10-12}$

Competency-based education has already been implemented by several academic institutions worldwide. These programs traditionally build credibility based on the evaluation of trainees' subsequent performance. ${ }^{13}$ 
These educational initiatives often rely too heavily on competencies developed by single training programs and, as such, lack a "common standards" framework. ${ }^{14}$ However, in this study, we strongly suggest that an agreed-upon set of cross-sectorial competencies would best provide the basis for standardized educational program framework. ${ }^{10,12,15,16}$ This would allow for the assessment of aid workers' performance and knowledge acquisition based on their designated tasks and would further ensure international recognition and best-practices comparison ${ }^{17}$ by regulatory stakeholders. ${ }^{14}$ Unfortunately, assessment of competency-based post-education and training skill sets has been sparse to date. ${ }^{18}$

This systematic review of peer-reviewed studies aims to identify existing competency sets for disaster management and humanitarian assistance that would serve as guidance for the development of a common disaster curriculum and content.

\section{METHODS}

\section{Study Design}

A systematic review was conducted according to the Preferred Reporting Items for Systematic Reviews and Meta-Analyses (PRISMA) checklist. ${ }^{19}$ The review included Englishlanguage papers published from January 2004 to January 2014 on PubMed, Google Scholar, Scopus, ERIC, and Cochrane Library.

\section{Data Collection}

A combination of the following keywords in the title was used: Disaster/s OR Public health emergency/ies OR Crisis/es OR Humanitarian OR Complex emergency/ies AND Competency/e/ies OR Ability/ies OR Knowledge OR Attitude/s OR Skill/s OR Professionalization. In addition, a grey-literature manual search was conducted to identify existing competency sets published on the websites of relevant universities, governmental organizations (GOs), nongovernmental organizations (NGOs), and other professional entities. Finally, an ancestry search was also performed to identify additional references on the reference section of the articles.

\section{Inclusion Criteria}

- Articles reporting competencies or competency domains, abilities, knowledge, skills, or attitudes for professionals involved in disaster relief or humanitarian assistance.

\section{Exclusion Criteria}

- Case studies;

- Abstracts;

- Citations;

- Articles not specifically related to abilities or performance;
- Articles not dealing with disasters or humanitarian assistance.

Titles and abstracts of the identified literature were scanned. Literature not complying with the inclusion criteria was excluded. The full text was obtained for uncertain articles, and references were independently screened and selected by two members of the research working group. When disagreement occurred, the opinion of a third reviewer was sought.

\section{Data Analysis}

References were described on the basis of their sectorial (eg, health, logistics, communication) and disciplinary approach (eg, emergency medicine, public health). Within a specific discipline, an additional distinction was made amongst different professional groups or cadres (eg, physicians, nurses, technicians) and proficiency levels (eg, informed worker/ student, practitioner, and leader). Target audiences (eg, physicians, nurses, social workers) were also analyzed. Out of the selected papers, we described how many of them reported either competency domains, competencies, or subcompetencies. Additionally, we analysed the method used by authors to define the competency domains, competencies, and subcompetencies. When identified, performance objectives were also reported.

\section{RESULTS}

The search strategy yielded a total of 1637 references; 3 additional articles resulted from the manual search on the web, and 15 were drawn from the reference sections of other articles. After exclusion of duplicates, 1151 titles were identified for further screening. A total of 1072 titles and abstracts were removed according to the exclusion criteria. This resulted in 79 full-text articles; 4 full-text articles could not be retrieved, and 37 did not meet the inclusion criteria, leaving 38 references for analysis (Figure 1). 2,4,5,14-16,20-51

Twenty-seven references were peer-review articles, $2,5,14-16,21,22,24,27-29,31-34,36,37,38-40,42,43,45,48-51$ one was a book chapter, ${ }^{4} 4$ were reports, ${ }^{25,26,41,44}$ and 6 were documents available on the websites of relevant organizations. ${ }^{20,23,30,35,46,47}$

Articles were referred to a single sector references. Only 5 (13\%) reported cross-sectorial competencies (Table 1). ${ }^{23,26,27,47,51}$ Most of the articles (81.6\%) were health care specific (Table 2) and, among them, 1 reported competencies for military health care staff. $^{42}$ Thirteen (34\%) articles referred to a single discipline, $18(47 \%)$ to at least 2 different disciplines, and $7(18 \%)$ were determined to be unclear as to discipline specificity by the reviewers (Table 1). Eighteen articles (47\%) included competencies for diverse professional groups. The most target audiences were nurses and disaster medicine and public health professionals (Table 3). 
FIGURE 1

\section{Review Selection Process and Results}

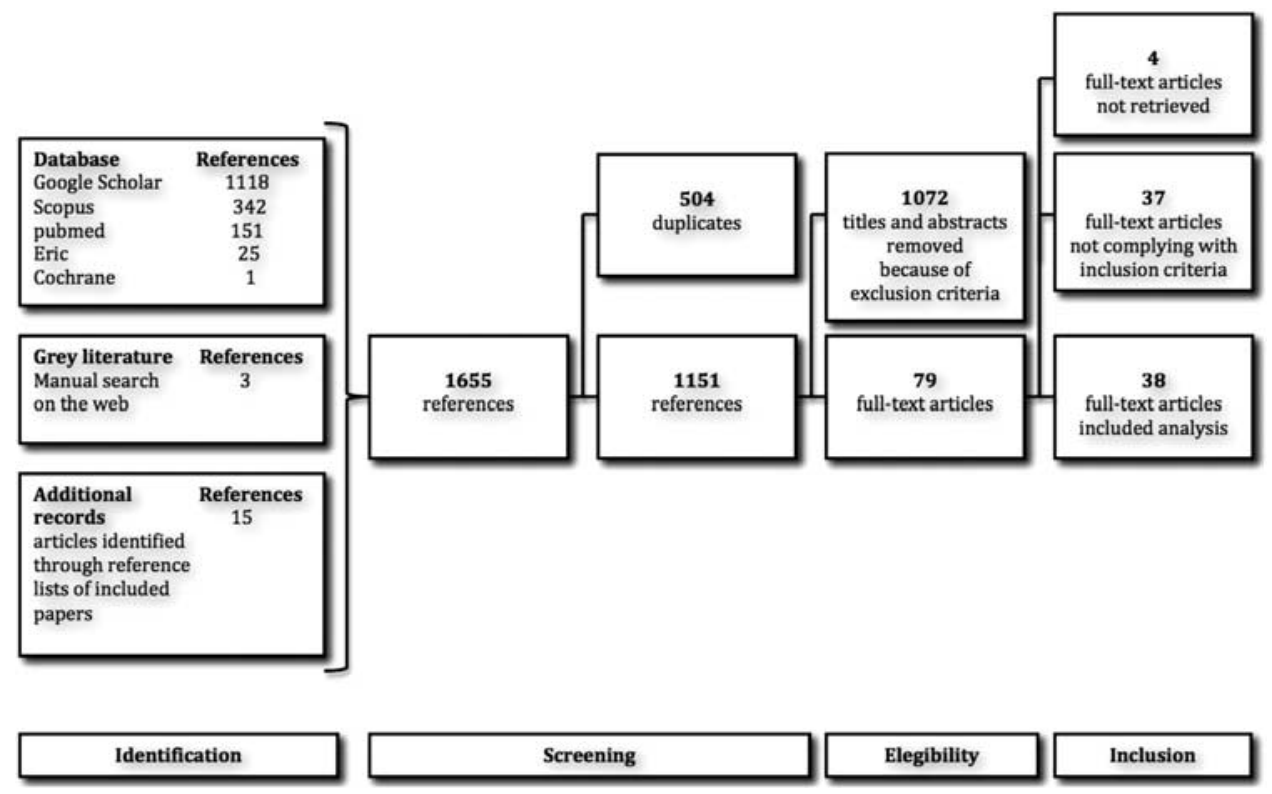

Of the articles reviewed that specified global humanitarian response, only 18 (47\%) articles defined competency domains. However, most of them referred to suggestive and poorly defined labels such as competency subject areas, ${ }^{22}$ competency areas, ${ }^{49}$ competency clusters,${ }^{26}$ and simply as competencies alone. . $^{33,35,41,46}$

Thirty-six papers (94\%) provided a list of competencies. Some authors named competencies as knowledge, ${ }^{25,51}$ competency description, ${ }^{31,41,49}$ skills, ${ }^{2,27,48,51}$ skills and knowledge, ${ }^{42,50}$ skills and traits, ${ }^{27,39}$ or behaviors. ${ }^{27}$ Only $5(13 \%)$ of the articles described subcompetencies and 5 (13\%) defined performance objectives. ${ }^{15,16,34,40,46}$

Thirty-one articles (81\%) clearly described the method adopted to define competencies. A total of 19 (50\%) used consensus-building, 5, 15, 16,20,22-26,28,29,31-33,40,41,43,46 3 articles identified competencies by survey or self-assessment questionnaires, ${ }^{27,37,48} 6$ reported competencies based solely on a literature review, ${ }^{2,14,39,42,49,50}$ and 4 reported or adapted competencies originally described by previously published articles. ${ }^{4,21,36,38}$

A total of 12 (31\%) defined competencies based on professional "responsibility" levels; 1 article defined competencies for frontline professional staff, ${ }^{21}$ supervisory and management staff, health officials and governance boards, and senior level professional staff; 1 reported different levels of expected proficiency according to the disciplines being considered; ${ }^{22}$ 1 supplied additional behaviors for first-level line managers in humanitarian response; and 2 included category-specific competencies for informed worker/students, practitioners, and leaders. ${ }^{5,24}$ One paper included competencies for basic-, mid-, and advanced-level personnel involved in both chemical and nonchemical environments; ${ }^{25}$ finally, 1 split competencies into 4 different levels of performance. ${ }^{26}$

\section{DISCUSSION}

This study reviewed the competencies published for professionals involved in disaster relief and humanitarian assistance regardless of their professional sector, discipline, role, or category.

Whereas the term competency embraces the set of knowledge, skills, and attitudes necessary to effectively and efficiently accomplish a task, this review revealed a lack of consensus even among the terminology used through different articles to define competency, competency domains, and so on. Likewise, a "competency statement" best describes the specific observable and measurable activities that individuals are able to perform. ${ }^{21,44,52}$ Thus, a competency statement would be expected to include an action verb, describing the level of performance (eg, apply, recognize), a description of the subject matter, type of performance, outcome performance, or specific operational task (eg, disaster response or recovery, public health emergency), and the context to which the competency statement is referred. ${ }^{21,52}$ To be effective, education and training require consensus on a set of core competencies with curricula based on a well-defined package of knowledge and skills. It is already well know that 
Summary of Data Extraction for the Selected Literature: $\checkmark$ Yes; O No; NS Not Specified

REF. YEAR TITLE

22013 Interprofessional non-technical skills for surgeons in disaster response: a literature review ${ }^{2}$

42012 Cross-Disciplinary Competency and Professionalization in Disaster Medicine and Public Health ${ }^{4}$

52008 A consensus-based educational framework and competency set for the discipline of disaster medicine and public health preparedness ${ }^{5}$

142010 A review of competencies developed for disaster health care providers:

limitations of current processes and applicability $^{14}$

152012 Core competencies for disaster medicine and public health ${ }^{15}$

162012 Development of national standardized all-hazard disaster core competencies for acute care physicians, nurses, and EMS professionals ${ }^{16}$

202010 Public health preparedness \& response core competency model ${ }^{20}$

212008 Assessing competencies for public health emergency legal preparedness $^{21}$

222005 Preparing health professions students for terrorism, disaster, and public health emergencies: core competencies ${ }^{22}$

232012 Core humanitarian competencies framework ${ }^{23}$

242010 Emergency preparedness and disaster response core competency set for perinatal and neonatal nurses ${ }^{24}$

252011 Recommended hospital staff core competencies for disaster preparedness $^{25}$

262006 Emergency capacity building project staff capacity initiative. Humanitarian competencies study ${ }^{26}$

\begin{tabular}{|c|c|c|c|c|c|c|c|c|c|}
\hline $\begin{array}{l}\text { Target } \\
\text { Audience } \\
\text { Clearly } \\
\text { Defined }\end{array}$ & $\begin{array}{c}\text { Multi- } \\
\text { Sectorial } \\
\text { Approach }\end{array}$ & $\begin{array}{c}\text { Multi- } \\
\text { Disciplinary } \\
\text { Approach }\end{array}$ & $\begin{array}{l}\text { Multi- } \\
\text { Professional } \\
\text { Group } \\
\text { Approach }\end{array}$ & $\begin{array}{c}\text { Include } \\
\text { Competency } \\
\text { Domains }\end{array}$ & $\begin{array}{c}\text { Include } \\
\text { Competencies }\end{array}$ & $\begin{array}{c}\text { Include } \\
\text { Subcompetencies/ } \\
\text { Competency } \\
\text { Descriptors }\end{array}$ & $\begin{array}{c}\text { Include } \\
\text { Performance } \\
\text { Objectives }\end{array}$ & $\begin{array}{c}\text { Define } \\
\text { Responsability/ } \\
\text { Proficiency } \\
\text { Levels }\end{array}$ & $\begin{array}{l}\text { Method } \\
\text { Adopted for } \\
\text { Competency } \\
\text { Definition } \\
\text { Clearly } \\
\text { Stated }\end{array}$ \\
\hline$\checkmark$ & $\mathbf{O}$ & NS & O & O & $\checkmark$ & O & $\mathbf{O}$ & $\mathbf{O}$ & $\checkmark$ \\
\hline$\checkmark$ & O & $\checkmark$ & $\checkmark$ & $\mathbf{O}$ & $\checkmark$ & O & O & $\checkmark$ & $\checkmark$ \\
\hline$\checkmark$ & O & $\checkmark$ & $\checkmark$ & $\checkmark$ & $\checkmark$ & O & O & $\checkmark$ & $\checkmark$ \\
\hline$\checkmark$ & $\mathbf{O}$ & $\checkmark$ & $\checkmark$ & $\checkmark$ & $\mathbf{O}$ & $\mathbf{O}$ & $\mathbf{O}$ & $\mathbf{O}$ & $\checkmark$ \\
\hline$\checkmark$ & $\mathbf{O}$ & $\checkmark$ & $\checkmark$ & O & $\checkmark$ & $\checkmark$ & $\checkmark$ & $\checkmark$ & $\checkmark$ \\
\hline$\checkmark$ & $\mathbf{O}$ & $\mathbf{O}$ & $\checkmark$ & $\checkmark$ & $\checkmark$ & O & $\checkmark$ & $\mathbf{O}$ & $\checkmark$ \\
\hline$\checkmark$ & O & O & $\checkmark$ & $\checkmark$ & $\checkmark$ & O & O & $\checkmark$ & $\checkmark$ \\
\hline$\checkmark$ & $\mathbf{O}$ & $\mathbf{O}$ & $\checkmark$ & $\checkmark$ & $\checkmark$ & $\mathbf{O}$ & $\mathbf{O}$ & $\checkmark$ & $\checkmark$ \\
\hline$\checkmark$ & O & $\checkmark$ & $\checkmark$ & $\checkmark$ & $\checkmark$ & O & O & $\checkmark$ & $\checkmark$ \\
\hline$\checkmark$ & $\checkmark$ & $\checkmark$ & $\checkmark$ & $\checkmark$ & $\checkmark$ & O & O & $\checkmark$ & $\checkmark$ \\
\hline$\checkmark$ & O & $\checkmark$ & $\checkmark$ & $\checkmark$ & $\checkmark$ & O & O & $\checkmark$ & $\checkmark$ \\
\hline$\checkmark$ & O & $\checkmark$ & $\checkmark$ & O & $\checkmark$ & $\mathbf{O}$ & $\mathbf{O}$ & $\checkmark$ & $\checkmark$ \\
\hline$\checkmark$ & $\checkmark$ & $\checkmark$ & $\checkmark$ & $\checkmark$ & $\checkmark$ & $\mathbf{O}$ & $\mathbf{O}$ & $\checkmark$ & $\checkmark$ \\
\hline
\end{tabular}


Table 1. Continued

\section{REF. YEAR TITLE}

272011 Crisis management competencies: The case of emergency managers in the $\mathrm{USA}^{27}$

282005 Development and implementation of a public health workforce training needs assessment survey in North Carolina ${ }^{28}$

292007 Expanding the public health emergency preparedness competency set to meet specialized local and evolving national needs: a needs assessment and training approach ${ }^{29}$

302004 Core public health worker competencies for emergency preparedness and response $^{30}$

312006 Preparing nurses internationally for emergency planning and response ${ }^{31}$

322008 Public health nursing competencies for public health surge events ${ }^{32}$

332008 American College of Occupational and Environmental Medicine competencies $^{33}$

342004 Predoctoral dental school curriculum for catastrophe preparedness 34

352004 Develop nursing students' disaster competency by working with the american red cross $^{35}$

362005 Assessing bioterrorism and disaster preparedness training needs for school nurses ${ }^{36}$

372012 Disaster Work in China: Tasks and Competences for Social Workers ${ }^{37}$

382005 Development of a training curriculum for public health preparedness ${ }^{38}$

392012 What Skills Are Needed to be a Humanitarian Logistician?39

402006 Health care worker competencies for disaster training ${ }^{40}$

412008 Integrating Emergency Preparedness and Response into Undergraduate Nursing Curricula ${ }^{41}$

\begin{tabular}{|c|c|c|c|c|c|c|c|c|c|}
\hline $\begin{array}{l}\text { Target } \\
\text { Audience } \\
\text { Clearly } \\
\text { Defined }\end{array}$ & $\begin{array}{c}\text { Multi- } \\
\text { Sectorial } \\
\text { Approach }\end{array}$ & $\begin{array}{l}\text { Multi- } \\
\text { Disciplinary } \\
\text { Approach }\end{array}$ & $\begin{array}{l}\text { Multi- } \\
\text { Professional } \\
\text { Group } \\
\text { Approach }\end{array}$ & $\begin{array}{l}\text { Include } \\
\text { Competency } \\
\text { Domains }\end{array}$ & $\begin{array}{c}\text { Include } \\
\text { Competencies }\end{array}$ & $\begin{array}{c}\text { Include } \\
\text { Subcompetencies/ } \\
\text { Competency } \\
\text { Descriptors }\end{array}$ & $\begin{array}{l}\text { Include } \\
\text { Performance } \\
\text { Objectives }\end{array}$ & $\begin{array}{c}\text { Define } \\
\text { Responsability/ } \\
\text { Proficiency } \\
\text { Levels }\end{array}$ & $\begin{array}{l}\text { Method } \\
\text { Adopted for } \\
\text { Competency } \\
\text { Definition } \\
\text { Clearly } \\
\text { Stated }\end{array}$ \\
\hline$\checkmark$ & $\checkmark$ & NS & NS & $\mathbf{O}$ & $\checkmark$ & $\mathbf{O}$ & $\mathbf{O}$ & $\checkmark$ & $\checkmark$ \\
\hline$\checkmark$ & O & O & $\checkmark$ & O & $\checkmark$ & O & O & O & $\checkmark$ \\
\hline$\checkmark$ & O & O & $\checkmark$ & O & $\checkmark$ & $\checkmark$ & O & O & $\checkmark$ \\
\hline$\checkmark$ & O & O & $\checkmark$ & O & $\checkmark$ & O & O & $\checkmark$ & NS \\
\hline$\checkmark$ & $\mathbf{O}$ & $\checkmark$ & O & O & $\checkmark$ & O & $\mathbf{O}$ & O & $\checkmark$ \\
\hline$\checkmark$ & O & O & O & O & $\checkmark$ & O & $\mathbf{O}$ & O & $\checkmark$ \\
\hline$\checkmark$ & O & O & O & $\checkmark$ & $\checkmark$ & O & $\mathbf{O}$ & O & $\checkmark$ \\
\hline$\checkmark$ & $\mathbf{O}$ & O & O & O & $\checkmark$ & O & $\checkmark$ & O & NS \\
\hline$\checkmark$ & $\mathbf{O}$ & $\mathbf{O}$ & O & $\checkmark$ & O & O & O & O & NS \\
\hline$\checkmark$ & $\mathbf{O}$ & $\mathbf{O}$ & O & O & $\checkmark$ & O & $\mathbf{O}$ & O & $\checkmark$ \\
\hline$\checkmark$ & $\mathbf{O}$ & $\mathbf{O}$ & $\mathbf{O}$ & $\checkmark$ & $\checkmark$ & $\mathbf{O}$ & $\mathbf{O}$ & $\mathbf{O}$ & $\checkmark$ \\
\hline$\checkmark$ & $\mathbf{O}$ & $\checkmark$ & NS & $\mathbf{O}$ & $\checkmark$ & $\mathbf{O}$ & $\mathbf{O}$ & $\mathbf{O}$ & $\checkmark$ \\
\hline$\checkmark$ & $\mathbf{O}$ & $\mathbf{O}$ & NS & $\mathbf{O}$ & $\checkmark$ & $\mathbf{O}$ & $\mathbf{O}$ & $\mathbf{O}$ & $\checkmark$ \\
\hline$\checkmark$ & $\mathbf{O}$ & $\checkmark$ & $\checkmark$ & $\mathbf{O}$ & $\checkmark$ & $\checkmark$ & $\checkmark$ & $\mathbf{O}$ & $\checkmark$ \\
\hline$\checkmark$ & $\mathbf{O}$ & $\checkmark$ & $\mathbf{O}$ & $\checkmark$ & $\checkmark$ & $\checkmark$ & $\mathbf{O}$ & $\mathbf{O}$ & $\checkmark$ \\
\hline
\end{tabular}


422013 Clinical skill and knowledge

requirements of health care providers

O

$\mathbf{O}$

$\mathbf{O}$

O

caring for children in disaster,

humanitarian and civic assistance

operations: an integrative review of the literature ${ }^{42}$

432005 Disaster competency development and integration in nursing education ${ }^{43}$

442009 ICN framework of disater nursing competencies $^{44}$

452008 On academics: training for disaster response personnel: the development of proposed core competencies in disaster mental health ${ }^{45}$

462009 Napa County Public Health Divison Public Health Preparedness ${ }^{46}$

472009 Humanitarian coordination competencies ${ }^{47}$

482011 A survey of the practice of nurses' skills in Wenchuan earthquake disaster sites: implications for disaster training ${ }^{48}$

492004 Emergency preparedness competencies: assessing nurses' educational needs ${ }^{49}$

502012 Knowledge and skills of Emergency Care During Disaster For Community Health

Volunteers: A Literature Review ${ }^{50}$

512004 Worker training for new threats: a proposed framework ${ }^{51}$

$\begin{array}{lllllll}\checkmark & \text { O } & \text { NS } & \text { O } & \checkmark & \checkmark & 0 \\ \checkmark & \checkmark & \text { NS } & \text { O } & \checkmark & \checkmark & 0 \\ \checkmark & \text { O } & \text { NS } & \text { O } & \text { o } & \checkmark & 0 \\ \checkmark & \text { O } & \text { NS } & \text { O } & \checkmark & \checkmark & 0 \\ \checkmark & \checkmark & \checkmark & \checkmark & 0 & \checkmark & 0\end{array}$

o

o

NS

o

o

o

$\mathbf{O}$

O

o

NS

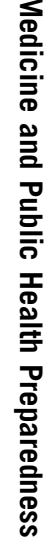




\section{TABLE 2}

$\begin{array}{ll}\text { References Categorized by Targeted Sector } \\ \text { Sector } & \text { References } \\ \text { Multisector } & 23,26,27,47,51 \\ \text { Health care sector } & 2,4,5,14-16,20-22,24,25,28-36, \\ & 38,40-46,48-50 \\ \text { Public/social welfare sector } & 37 \\ \text { Consumer goods/operational sector } & 39\end{array}$

\section{TABLE 3}

\begin{tabular}{|ll|}
\hline \multicolumn{2}{|l|}{ References Categorized by } \\
Audience & References \\
& \\
Social workers & 37 \\
Volunteers & 50 \\
Medical reserve corps & 46 \\
Humanitarian personnel & $23,26,39,47$ \\
Crisis managers & 27 \\
Disaster workers & 51 \\
Military health care providers & 42 \\
Disaster medicine professionals & $4,5,15,29,45$ \\
Public health professionals & $4,5,10,15,20,21,28,29,30,38,45$ \\
Disaster health care professionals & 14 \\
Acute care medical professionals & 16 \\
Occupational and environmental & 33 \\
physicians & \\
Dentists & 34 \\
Surgeons & 2 \\
Hospital personnel & 25,40 \\
Nurses & $24,31,32,36,43,44,48,49$ \\
Health students & $22,35,41$ \\
\hline
\end{tabular}

competency-based education and training represents the cornerstone in the professionalization of disaster medicine and humanitarian aid. ${ }^{53}$ Ultimately, definitional uniformity will also facilitate the establishment of this discipline at an operational level.

In a previous study, the disagreement in the terminology used among articles in defining these concepts was attributed to a general lack of understanding of the competency-based education framework or foundation building-process, ${ }^{14}$ subcompetencies, and performance objectives.

While competency statements include a broad description of a task, performance objectives describe a specific outcome that workers are expected to accomplish as a result of their work activity. ${ }^{54}$ Furthermore, they define measurable goals that can be used to evaluate learning ${ }^{40}$ and, therefore, are necessary to assess whether or not students gain new competencies as result of their participation in education and training programs. However, only a few among the selected articles reported performance objectives.
The lack of homogeneity in terms of competency definition and related characteristics-such as performance objectives or specific expected outcome-poses an additional challenge to educational designers in the field of humanitarian assistance and disaster management. A previous study showed, in fact, that only $61 \%$ of the educational and training initiatives offered in European countries have a competency-based curriculum design. ${ }^{55}$

Little agreement on the terminology used was also found in the definition of proficiency levels within target groups. In 2011, an internationally accepted framework to define target audiences on the basis of their level of responsibility was developed: strategic-level (gold), tactical-level (silver), and operational (bronze). ${ }^{56}$ A common terminology, would facilitate the ongoing standardization process in education, certification (among providers), and accreditation (among academic-affiliated education and training institutions) in disaster response and humanitarian assistance.

It is a well-recognized consensus that all the professionals involved in disaster preparedness and response (eg, search and rescue, fire brigades, etc) should receive specific training regardless of the professional sector to which they belong. ${ }^{55}$

However, even if this literature review has been conducted through different search engines, including but not limited to medical databases, the vast majority of articles reviewed still reported competencies directed to the health care sector. Accordingly, similar results came from an analysis on training opportunities in mass destruction weapons (CBRNE), including the following professional sectors: general manufacturing, transportation, health care, emergency response, and skilled support. ${ }^{51}$

As such, this expanded the available competencies and resulted in considerably more training opportunities for health care workers compared to other professional sectors.

It is crucial to underline that while health care plays a relevant role in disaster response, education must also be extended to other actors equally involved in disaster management. Indeed, international standards on education and training in the field for disaster management emphasize that education and training programs should be both multidisciplinary and transdisciplinary and based on a modular approach $;^{57}$ this strongly implies that the definition of relevant competencies must first consider the wide audience the education and training might include.

Most articles were nursing-centric. Since September 11, 2001, numerous efforts have been made to enhance preparedness within this specific professional group, as they are early responders to disasters, represent skilled human resources within the health sector, and play active roles in national preparedness plans. ${ }^{43}$ Among the studies that included multidisciplinary competencies, that of the American Medical 
Association Center for Public Health Preparedness and Disaster Response provides a comprehensive consensus-based set of competencies that integrates all the health specialties involved in disaster medicine and public health. ${ }^{5}$

Supporting previous research, the majority of the competency sets were based on consensus building. ${ }^{14}$ However, surveys have also demonstrated a method to extract competencies, skills, and behaviors based on the opinion and field experience of a number of providers from the target audience. The combination of both methods could provide good evidence on the existing educational gaps from an academic and operational standpoint.

While searching peer-reviewed literature yielded a number of articles, several papers were reports, and others were webbased resources that were not accessible through the search engines utilized. This demonstrates that over the last decade, several competency sets for professionals working in disaster response and humanitarian assistance have been developed; however, some of them remain published as grey literature.

\section{Limitations}

This search was restricted to English-language articles, which might have narrowed our search spectrum; however, it is a comprehensive systematic review and covers most of competency-based disaster education and training elements in the studies reviewed.

This study only included articles published over the last decade. Related studies that could have supplied relevant information but fell outside this time period were not taken into consideration.

Even if it would have been useful and of great interest to develop a comprehensive competency framework on the basis of all the competencies provided by the articles reviewed, the huge number of competencies listed - along with the aforementioned lack of standard terminology — made this task difficult if not impossible to accomplish. However, it is hoped that this study will draw attention to the potential causes that currently prevent professionals in disaster medicine and humanitarian action from receiving a standardized and globally recognized education and training opportunities. The authors suggest that more directed research, discussions, and debates on the reasons for these gaps is required before the expected level of professionalism is realized.

\section{CONCLUSIONS}

This systematic literature review revealed a huge number of competencies published over the last decade for different professional sectors involved in disaster response and humanitarian assistance. Studies reviewed (both peer reviewed and grey literature) were mainly focused on the health care sector and presented a lack of agreement on the terminology used for competency-based definition and phrasing. The most targeted discipline was nursing, and the main method adopted for competency development was consensus building. Further engagement to standardize competency-based education in disaster medicine and humanitarian assistance is needed; the development and validation of a common competencyframework for all the professionals involved in crisis response will represent a decisive step forward for professionalization and certification and will facilitate greater accountability, transparency, and performance oversight.

\section{About the Authors}

CRIMEDIM, Università del Piemonte Orientale, Novara, Italy (Dr Ripoll Gallardo, Dr Djalali, Dr Foletti, Dr Ragazzoni, Dr Della Corte, Dr Ingrassia); URGENTA, Clinical Emergency Hospital, Bucharest, Romania (Dr Lupescu); Hanover Associates, Teddington, London, UK (Mr. Arculeo); NHCS, National Health Career School of Management, Hennigsdorf/Berlin, Germany (Dipl-Ing von Arnim, Mr Friedl); Bonn International Center for Conversion, Bonn, University Clinic Bonn Department of Orthopedics and Trauma Surgery, Bonn, Germany (Dr Ashkenazi, Dr Fisher); CROUMSA, Croatian Urgent Medicine and Surgery Association, Slav. Brod, Croatia (Dr Hreckovski); Prehospital and Disaster Medicine Centre, Sahlgrenska Academy, Gothenburg, Sweden (Dr KhorramManesh); SBC, General $\mathcal{B}$ Teaching Hospital Celje, Medical Faculty Ljubljana, Slovenia (Dr Komadina); German Aerospace Center (DLR), Oberpfaffenhofen, Germany (Dr Lechner); Global Risk Forum GRF Davos, Davos, Switzerland (Dipl Geo Stal); Clinical Emergency Hospital Bucharest, Romania (Dr Patru); and Harvard Humanitarian Initiative, Cambridge, Massachusetts (Dr Burkle).

Correspondence and reprint requests to Alba Ripoll Gallardo, Centro di Ricerca Interdipartimentale in Medicina d'Emergenza e dei Disastri (CRIMEDIM), Università del Piemonte Orientale Via Ferrucci 33/Via Lanino 1, 28100 Novara, Italy (e-mail: ripoll@med.unipmn.it).

\section{Acknowledgments}

Authors wish to thank all the DITAC Project members for their contribution and assistance in conducting the research activities that allowed us to write this manuscript.

\section{Funding}

This research is part of the activities of the Disaster Training Curriculum (DITAC) project funded by the European Community's Seventh Framework Programme (FP7/2007-2013) under grant agreement n² 285036.

\section{Conflict of Interest}

There are no situations which this manuscript that may be perceived as conflict of interest or as a copyright constraint.

Published online: May 5, 2015.

\section{REFERENCES}

1. Guha-Sapir D, Hoyois P, Below R. Annual Disaster Statistical Review 2013: The Numbers and Trends. http://cred.be/sites/default/files/ ADSR_2013.pdf. Published September 2014. Accessed December 10, 2014.

2. Willems A, Waxman B, Bacon AK, et al. Interprofessional nontechnical skills for surgeons in disaster response: a literature review. J Interprof Care. 2013;27:380-386.

3. Birch M, Miller S. Humanitarian assistance: standards, skills, training, and experience. BMJ. 2005;21:1199-1201.

4. Burkle FM Jr, Lyznicki JM, James JJ. Cross-disciplinary competency and professionalization in disaster medicine and public health. In: Gursky E, 
Hreckovski B, eds. Handbook for Pandemic and Mass-Casualty Planning and Response 2012. Amsterdam: IOS Press; 2012:72-83.

5. Subbarao I, Lyznicki JM, Hsu EB, et al. A consensus-based educational framework and competency set for the discipline of disaster medicine and public health preparedness. Disaster Med Public Health Prep. 2008;2:57-68.

6. Djalali A, Ingrassia PL, Corte FD, et al. Identifying deficiencies in national and foreign medical team responses through expert opinion surveys: Implications for education and training. Prehosp Disaster Med. 2014;19:1-5.

7. McCall C. Scars of typhoon Haiyan still run deep 1 year on. Lancet. 2014;384(9955):1656-1657.

8. Yamada S, Galat A. Typhoon Yolanda/Haiyan and climate justice. Disaster Med Public Health Prep. 2014;8:432-435.

9. Cranmer $\mathrm{HH}$, Biddinger PD. Typhoon Haiyan and the professionalization of disaster response. N Engl J Med. 2014;27:1185-1187.

10. Johnson K, Idzerda L, Baras R, et al. Competency-based standardized training for humanitarian providers: making humanitarian assistance a professional discipline. Disaster Med Public Health Prep. 2013;7:369-372.

11. Bradt DA, Drummond CM. Professionalization of disaster medicine-an appraisal of criterion-referenced qualifications. Prehosp Disaster Med. 2007;22:360-368

12. Burkle FM Jr. The development of multidisciplinary core competencies: the first step in the professionalization of disaster medicine and public health preparedness on a global scale. Disaster Med Public Health Prep. 2012;6:10-12

13. Leung WC. Competency based medical training: review. BMJ. 2002;325:693-696.

14. Daily E, Padjen P, Birnbaum M. A review of competencies developed for disaster healthcare providers: limitations of current processes and applicability. Prehosp Disaster Med. 2010;25:387-395.

15. Walsh L, Subbarao I, Gebbie K, et al. Core competencies for disaster medicine and public health. Disaster Med Public Health Prep. 2012;6: 44-52.

16. Schultz CH, Koenig KL, Whiteside M, et al. National Standardized All-Hazard Disaster Core Competencies Task F. Development of national standardized all-hazard disaster core competencies for acute care physicians, nurses, and EMS professionals. Ann Emerg Med. 2012;59: 196-208 e1.

17. Kako M, Mitani S. A literature review of disaster nursing competencies in Japanese nursing journals. Collegian. 2010;17:161-173.

18. Cranmer H, Chan JL, Kayden S, et al. Development of an evaluation framework suitable for assessing humanitarian workforce competencies during crisis simulation exercises. Prehosp Disaster Med. 2014;29:69-74.

19. Liberati A, Altman DG, Tetzlaff J, et al. The PRISMA statement for reporting systematic reviews and meta-analyses of studies that evaluate health care interventions: explanation and elaboration. J Clin Epidemiol. 2009;62:e1-34.

20. Centers for Disease Control and Prevention (CDC). Public Health Preparedness \& Response Core Competency Model. http://www.cdc.gov/ phpr/documents/perlcPDFS/PreparednessCompetencyModelWorkforceVersion1_0.pdf. Published 2010. Accessed May 7, 2014.

21. Hodge JG, Jr., Gebbie KM, Hoke C, et al. Assessing competencies for public health emergency legal preparedness. J Law Med Ethics. 2008; 36(1 Suppl):28-35

22. Markenson D, DiMaggio C, Redlener I. Preparing health professions students for terrorism, disaster, and public health emergencies: core competencies. Acad Med. 2005;80:517-526.

23. The consortium of British Humanitarian Agencies (CBHA). Core humanitarian competencies framework. http://www.euprha.org/wp-content/ uploads/2013/08/CBHA-Competencies-Framework-2012.pdf. Published 2012. Accessed May 7, 2014.

24. Jorgensen AM, Mendoza GJ, Henderson JL. Emergency preparedness and disaster response core competency set for perinatal and neonatal nurses. J Obstet Gynecol Neonatal Nurs. 2010;39:450-465.
25. Florida Department of Health 2011. Recommended hospital staff core competencies for disaster preparedness. http://iroquois.org/userfiles/ hospitalcorecompetencies.pdf. Published 2011. Accessed April 30, 2014.

26. Emergency Capacity Building Project 2006. Emergency Capacity Building Project staff capacity initiative. Humanitarian competencies study. http://www.euprha.org/wp-content/uploads/2013/08/ECB-projectHumanitarian-Competencies-Study-report-2006.pdf. Published 2006. Accessed May 7, 2014.

27. Van Wart M, Kapucu N. Crisis management competencies: the case of emergency managers in the USA. Public Manage Rev. 2011;13:489-511.

28. Harrison LM, Davis MV, MacDonald PD, et al. Development and implementation of a public health workforce training needs assessment survey in North Carolina. Public Health Rep. 2005;120(Suppl 1):28-34.

29. Hites LS, Lafreniere AV, Wingate MS, et al. Expanding the public health emergency preparedness competency set to meet specialized local and evolving national needs: a needs assessment and training approach. J Public Health Manag Pract. 2007;13:497-505.

30. Columbia University. Core public health worker competencies for emergency preparedness and response. http://www.phf.org/resourcestools/ Documents/emergencypreparednesscorecompetencies_Columbia_University. pdf. Published April 2001. Accessed April 30, 2014.

31. Weiner E. Preparing nurses internationally for emergency planning and response. Online J Issues Nurs. 2006;11:4.

32. Polivka BJ, Stanley SA, Gordon D, et al. Public health nursing competencies for public health surge events. Public Health Nurs. 2008;25:159-165.

33. American College of Occupational and Environmental Medicine (ACOEM). American College of Occupational and Environmental Medicine competencies-2008. J Occup Environ Med. 2008;50:712-724.

34. More FG, Phelan J, Boylan R, et al. Predoctoral dental school curriculum for catastrophe preparedness. J Dent Educ. 2004;68:851-858.

35. American Red Cross. Develop nursing students' disaster competency by working with the American Red Cross. http://www.westga.edu/ vickir/ Healthcare/HC10 Identity/Link 5 - ARC Nursing Student Disaster Competency PDF.pdf. Published 2004. Accessed April 29, 2014.

36. Mosca NW, Sweeney PM, Hazy JM, et al. Assessing bioterrorism and disaster preparedness training needs for school nurses. J Public Health Manag Pract. November 2005; Suppl:S38-S44.

37. T NG. Disaster work in China: Tasks and competences for social workers. Social work education. 2012;31:538-556.

38. Rottman SJ, Shoaf KI, Dorian A. Development of a training curriculum for public health preparedness. J Public Health Manag Pract. 2005; Suppl: S128-S131.

39. Kovács $G$, Tatham $P$, Larson $D$. What skills are needed to be a humanitarian logistician? J Bus Logistics. 2012;33:245-258.

40. Hsu EB, Thomas TL, Bass EB, et al. Healthcare worker competencies for disaster training. BMC Med Educ. 2006;6:19.

41. World Health Organization (WHO). Preparedness, integrating emergency. "Integrating emergency preparedness and response into undergraduate nursing curricula." http://www.who.int/hac/publications/ Nursing_curricula_followup_Feb08.pdf. Published February 2008. Accessed June 2, 2014

42. Johnson HL, Gaskins SW, Seibert DC. Clinical skill and knowledge requirements of health care providers caring for children in disaster, humanitarian and civic assistance operations: an integrative review of the literature. Prehosp Disaster Med. 2013;28:61-68.

43. Stanley JM. Disaster competency development and integration in nursing education. Nurs Clin North Am. 2005;40:453-467.

44. World Health Organization (WHO). ICN framework of disaster nursing competencies. http://myweb.polyu.edu.hk/ hswhocc/resource/D/2009Disaster NursingCompetencies.pdf. Published 2009. Accessed April 30, 2014.

45. Everly GS Jr., Beaton RD, Pfefferbaum B, et al. On academics: training for disaster response personnel: the development of proposed core competencies in disaster mental health. Public Health Rep. 2008;123:539-542.

46. Napa County 2009. NAPA County Public Health Division-public health preparedness. http://www.countyofnapa.org/publichealth/mrccorecompetencies/. Published 2009. Accessed May 7, 2014. 
47. Humanitarian coordination competencies. http://www.google.it/url?sa= $\mathrm{t} \& \mathrm{rct}=\mathrm{j} \& \mathrm{q}=\&$ esrc $=\mathrm{s} \&$ source $=$ web $\& \mathrm{~cd}=1 \& \mathrm{ved}=0 \mathrm{CDgQFjAA} \& u r l=$ http\%3A\%2F\%2Fwww.humanitarianinfo.org\%2Fiasc\%2Fdownloaddoc. aspx\%3FdocID\%3D5090\%26type\%3Dpdf\&ei=Q3ZmUrDMcGb0QWW 7oG4Dg\&usg=AFQjCNFJhB_08XCW53hFLuWXcY_xqUU3ew\&sig2= lbOF-OUYpsR9x3OMp7tVUw. Published 2009. Accessed May 7, 2014. Humanitarian coordination competencies 2006.

48. Yin $\mathrm{H}, \mathrm{He} \mathrm{H}$, Arbon $\mathrm{P}$, et al. A survey of the practice of nurses' skills in Wenchuan earthquake disaster sites: implications for disaster training. J Adv Nurs. 2011;67:2231-2238.

49. Wisniewski R, Dennik-Champion G, Peltier JW. Emergency preparedness competencies: assessing nurses' educational needs. J Nurs Adm. 2004;34:475-480.

50. Kamal A, Songwathana P, Sia SW. Knowledge and skills of emergency care during disaster for community health volunteers: a literature review. Nurse Media Journal of Nursing. 2012;2:371-381.

51. Mitchell CS, Doyle ML, Moran JB, et al. Worker training for new threats: a proposed framework. Am J Ind Med. 2004;46: 423-431.
52. Gebbie K, Standish E. Competency-to-curriculum toolkit: developing curricula for public health workers. http://www.asph.org/userfiles/ competency-to-curriculum-toolkit08.pdf. Published 2012. Accessed May 1, 2014.

53. Burkle FM. Conversations in disaster medicine and public health: the profession. Disaster Med Public Health Prep. 2014;8:5-11.

54. Defense Civilian Intelligence Personnel System (DCIPS) 2009. Guide to writing effective performance objectives, self accomplishments and evaluations. http://dcips.dtic.mil/documents/Guide_Writing_Effective_ Objectives.pdf. Published Fall 2009. Accessed June 3, 2014.

55. Ingrassia PL, Foletti M, Djalali A, et al. Education and training initiatives for crisis management in the European Union: a web-based analysis of available programs. Prehosp Disaster Med. 2014;29:115-126.

56. Wallis L, Smith W. Disaster medicine South Africa. Salt Lake City: Academic Press. 2011.

57. Seynaeve G, Archer F, Fisher J, et al. International standards and guidelines on education and training for the multi-disciplinary health response to major events that threaten the health status of a community. Prehosp Disaster Med. 2004;19:S17-S30. 